
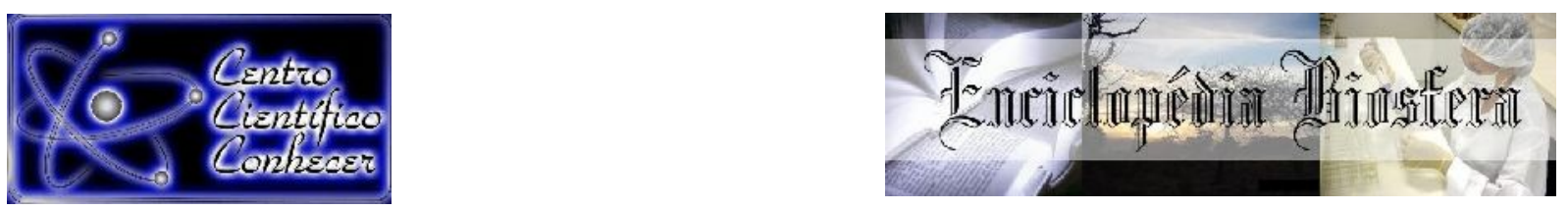

\title{
CONTROLE DE Sclerotinia sclerotiorum E Fusarium sp. COM ÓLEO ESSENCIAL DE MELALEUCA
}

\author{
Gerusa Pauli Kist Steffen ${ }^{1}$, Joseila Maldaner ${ }^{1}$, Ricardo Bemfica Steffen ${ }^{2}$, Evandro \\ Luiz Missio ${ }^{1}$, Ricardo Mezzomo ${ }^{3}$ \\ ${ }^{1}$ Pesquisador(a) Doutor(a) - Centro de Pesquisa em Florestas (DDPA/SEAPDR), \\ Santa Maria, Rio Grande do Sul-ge.pauli@yahoo.com.br \\ ${ }^{2}$ Pós-doutorado em Ciência do Solo pela Universidade Federal de Santa Maria, \\ Santa Maria, Rio Grande do Sul \\ ${ }^{3}$ Doutorado em Engenharia Florestal pela Universidade Federal de Santa Maria, \\ Santa Maria, Rio Grande do Sul
}

Recebido em: 04/10/2019 - Aprovado em: 30/11/2019 - Publicado em: 15/12/2019

DOI: $10.18677 /$ EnciBio_2019B14

\begin{abstract}
RESUMO
Melaleuca alternifolia é uma espécie florestal originária da Austrália, com abundante presença de óleo essencial de interesse econômico devido às reconhecidas propriedades bactericida e antifúngica contra patógenos humanos. O objetivo deste trabalho foi avaliar o efeito de concentrações do óleo essencial de melaleuca sobre o crescimento in vitro de Sclerotinia sclerotiorum e Fusarium sp, fitopatógenos de relevante importância agrícola. Concentrações crescentes de óleo essencial de melaleuca $(0 ; 0,1 ; 0,25 ; 0,5 \%)$ foram solubilizadas em meio de cultura batata-dextrose-ágar. Os meios foram vertidos em placas de Petri $(90 \mathrm{~mm}$ de diâmetro), seguido da deposição de um disco de micélio fúngico (9 $\mathrm{mm}$ de diâmetro) dos fitopatógenos avaliados. As placas foram incubadas em temperatura de $25 \pm 1{ }^{\circ} \mathrm{C}$ e fotoperíodo de 12 horas. $\mathrm{O}$ crescimento micelial foi avaliado através da determinação do diâmetro médio das colônias com auxílio de paquímetro digital, decorridas 72 e 96 horas de incubação. A partir dos dados de crescimento, determinou-se a porcentagem de inibição do crescimento micelial. $O$ óleo essencial de melaleuca apresentou efeito antifúngico aos fitopatógenos $S$. slerotiorum e Fusarium sp. As concentrações de 0,5\% promoveram $100 \%$ de inibição do crescimento de ambos os gêneros fúngicos. Considerando os resultados obtidos neste trabalho, o óleo essencial de melaleuca demonstrou potencial para composição de bioprodutos destinados ao uso agrícola.
\end{abstract}

PALAVRAS-CHAVE: Atividade antifúngica, Melaleuca alternifolia, Metabólitos secundários. 


\title{
CONTROL OF Sclerotinia sclerotiorum AND Fusarium sp. WITH MELALEUCA ESSENTIAL OIL
}

\begin{abstract}
Melaleuca alternifolia is a forest species from Australia, with abundant presence of essential oil with economic interest due to the recognized bactericidal and antifungal properties against human pathogens. The objective of this article was to evaluate the effect of melaleuca essential oil concentrations on the in vitro growth of Sclerotinia sclerotiorum and Fusarium sp., phytopathogens of relevant agricultural importance. Increasing concentrations of $M$. alternifolia essential oil $(0.1 ; 0.25 ; 0.5 \%)$ were solubilized in potato-dextrose-agar culture medium. The culture medium were poured into Petri dishes (90 $\mathrm{mm}$ diameter), followed by the deposition of a fungal mycelium disc ( $9 \mathrm{~mm}$ diameter) of the phytopathogens. Petri dishes were incubated at $25 \pm 1{ }^{\circ} \mathrm{C}$ and photoperiod of 12 hours. Mycelial growth was evaluated by determining the average diameter of the colonies with the aid of a digital caliper after 72 and 96 hours of incubation. The percentage inhibition was determined from the growth data. Melaleuca essential oil showed antifungal effect to S. slerotiorum and Fusarium sp. Concentrations of $0.5 \%$ promoted $100 \%$ growth inhibition of both fungal genera. Considering the results obtained in this study, the melaleuca essential oil showed potential for the composition of bioproducts for agricultural use.
\end{abstract}

KEYWORDS: Antifungal activity, Melaleuca alternifolia, Secondary metabolites.

\section{INTRODUÇÃO}

A simplificação da diversidade vegetal em ambientes agrícolas impacta de forma negativa a biodiversidade microbiológica do solo, causando desequilíbrio nas cadeias alimentares das outras formas de vida que habitam o mesmo agrossistema. O surgimento de pragas é um reflexo direto de desequilíbrios provocados pelos monocultivos, especialmente naqueles que não utilizam sistemas de rotação de culturas. O uso contínuo e intensivo de pesticidas na agricultura é mais um fator que interfere negativamente sobre o ambiente, pois embora apresente efeito imediato sobre a redução da população de pragas nos cultivos, possui efeitos negativos a médio e longo prazo (MOORMAN, 2018; BOUDH ; SINGH, 2019; JAISWAL et al., 2019). Isto porque a maioria dos agrotóxicos atua não somente nos organismos alvo, mas também sobre organismos benéficos que atuam naturalmente no controle biológico de pragas. Não obstante, o uso excessivo do controle químico tem levado ao surgimento de várias formas de resistência em insetos, fungos fitopatogênicos e plantas invasoras, o que induz o aumento do número de aplicações de diferentes tipos de agroquímicos, elevando os custos de produção e promovendo contaminação do solo, da água, do homem e dos animais (BURIGO, 2016; LOPES ; ALBUQUERQUE, 2018).

Diante desta preocupante realidade, verifica-se um interesse crescente por parte da sociedade e dos setores ligados à agricultura, pela adoção de estratégias e tecnologias alternativas para o manejo de pragas, que além de eficientes, sejam tecnicamente viáveis e ambientalmente seguras (RIBEIRO et al., 2016; SOUZA et 
al., 2018; NICOLODI-CAMERA et al., 2018). Dentre as alternativas que tem conquistado destaque no cenário mundial, o uso de moléculas naturais extraídas de plantas bioativas vem demonstrando resultados promissores (MAIA et al., 2015).

Óleos essenciais de espécies vegetais são utilizados há décadas no controle alternativo de microrganismos patogênicos (POWERS et al., 2018). São formados por misturas complexas de compostos voláteis, sendo constituídos majoritariamente por terpenos ou seus derivados (FELIPE ; BICAS, 2017), que apresentam reconhecida atividade antimicrobiana (MARTINO et al., 2015; LUTFI ; ROQUE, 2014). Os compostos voláteis presentes nos óleos essenciais podem atuar na mortalidade ou repelência de insetos, dificultando sua alimentação ou reprodução, além de impedir a proliferação de fungos prejudiciais e controlar a germinação e crescimento de ervas daninhas competidoras (PETERS, 2016). O fato de apresentarem atividades fungistática, inseticida e herbicida torna os óleos essenciais objeto de interessante investigação e aplicação nos diversos setores da agropecuária.

Sclerotinia sclerotiorum (Lib.) De Bary e espécies do complexo Fusarium Link ex Grey representam importantes fitopatógenos responsáveis por perdas significativas em variados cultivos agrícolas (TAYLOR et al., 2018). A doença conhecida como mofo branco, podridão branca ou podridão da haste de sclerotinia é causada pelo fungo $S$. sclerotiorum, um patógeno inespecífico capaz de infectar mais de 400 espécies vegetais, com destaque para os cultivos de soja, feijão, fumo, girassol, canola, ervilha, bata e tomate (LEITE, 2005). Este fitopatógeno de difícil controle no solo ocorre em diversos países, principalmente em regiões de clima temperado e subtropical (BIANCHINI et al., 2005). Da mesma forma, espécies do gênero Fusarium são associadas a doenças de importância agrícola, tais como: murcha-de-fusário em soja, tomate e feijão, podridão-radicularvermelha em soja, mal-do-panamá em bananeira, podridão do caule em café e podridão-de-fusário em citros (MICHEREFF et al., 2005), causando redução no percentual de emergência e tombamento de plântulas (MIGLIORINI et al., 2018).

A atividade antimicrobiana observada em diferentes óleos essenciais está relacionada a determinados constituintes, tais como monoterpenos, compostos fenólicos e terpenoides, sendo o potencial fungicida dependente das concentrações testadas (MAIA et al., 2015). A Melaleuca alternifolia Cheel é uma espécie aromática pertencente à família Myrtaceae, comumente conhecida como "árvore de chá" (Tea tree) originária da Austrália, e com grande interesse econômico devido à presença de óleo volátil armazenado no tecido foliar (MARTINS et al., 2011). Seu óleo essencial apresenta grande importância medicinal, pois possui comprovada ação bactericida e antifúngica contra patógenos humanos (HAMMER et al., 2004; PACKER ; LUZ, 2007; POWERS et al., 2018).

Seu uso para finalidades agrícolas ainda é pouco explorado, embora alguns estudos já tenham comprovado a ação fungicida do óleo essencial de melaleuca contra fitopatógenos (BARBOSA et al., 2015, FIALHO et al., 2015; SOUZA et al., 2015). Desta forma, o objetivo do trabalho foi avaliar o efeito de concentrações do 
óleo essencial de melaleuca sobre o crescimento in vitro de Sclerotinia sclerotiorum e Fusarium sp.

\section{MATERIAL E MÉTODOS}

Foram avaliados cinco tratamentos e quatro repetições: controle (água destilada); controle álcool; 0,$1 ; 0,25$; e $0,5 \%$ (v/v) do óleo essencial de melaleuca diluído em álcool. Para possibilitar a completa solubilização do óleo no meio de cultura, realizou-se diluição em álcool etílico $99 \%$ (1:1 - v/v) antes da composição dos tratamentos. O controle álcool foi estabelecido com a maior concentração de álcool utilizada na diluição, a fim de se descartar o efeito deste componente nos tratamentos.

O óleo essencial de $M$. alternifolia utilizado neste estudo foi fornecido pela Empresa Vimontti - Agroindústria São Caetano Ltda ${ }^{\circledR}$, extraído pelo método de arraste a vapor. A análise da caracterização dos compostos do óleo essencial foi realizada por cromatografia gasosa na central de análises do Instituto de Biotecnologia da Universidade de Caxias do Sul, RS.

As soluções dos respectivos tratamentos foram adicionadas ao meio de cultura batata-dextrose-água (BDA) ainda líquido, após 0 processo de esterilização (25 minutos a $1^{2} 0^{\circ} \mathrm{C}$ e 1 ATM). Após homogeneização das concentrações do óleo essencial ao meio de cultura, estes foram vertidos em placas de Petri (90 mm de diâmetro). Decorrida a solidificação do meio de cultura, discos de BDA (9 $\mathrm{mm}$ de diâmetro) contendo micélio fúngico dos fitopatógenos com sete dias de crescimento foram depositados no centro das placas de Petri, as quais foram incubadas à temperatura de $25 \pm 1^{\circ} \mathrm{C}$ e fotoperíodo de 12 horas, durante 96 horas. Os isolados fitopatogênicos de $S$. sclerotiorum e Fusarium sp. (isolados T1R3 e T4R3) foram fornecidos pelo Laboratório de Fitopatologia da Universidade Federal de Santa Maria, RS.

As avaliações consistiram em medições do diâmetro das colônias com auxílio de paquímetro digital, decorridas 72 horas após a incubação e finalizadas após 96 horas, quando as colônias fúngicas do tratamento controle atingiram toda a superfície do meio de cultura. A partir dos dados de crescimento, determinou-se a porcentagem de inibição do crescimento micelial através da fórmula: $\mathrm{PICM}=$ [(DTT - DT) /DTA] x 100, onde: PICM = porcentagem de inibição do crescimento micelial, DTT = diâmetro no tratamento testemunha; DT= diâmetro do tratamento; DTA = diâmetro no tratamento avaliado. Os dados obtidos foram comparados pelo teste de Tukey a $5 \%$ de probabilidade de erro com auxílio do software SISVAR (FERREIRA, 2011).

\section{RESULTADOS E DISCUSSÃO}

Foram identificados 26 compostos no óleo essencial de $M$. alternifolia (Tabela 1). A composição e concentração dos compostos obtidos corroboram com os descritos na literatura referentes à composição de óleos essenciais extraídos de plantas do gênero Melaleuca (POWERS et al., 2018). 
TABELA 1 - Composição do óleo de Melaleuca alternifolia. Santa Maria - RS, 2019.

\begin{tabular}{|c|c|c|c|}
\hline Composto & \% Relativa* & Composto & \% Relativa \\
\hline Terpienen-4-ol & 36,02 & $\alpha$-tujeno & 0,74 \\
\hline$y$-terpineno & 18,69 & $\alpha$-felandreno & 0,69 \\
\hline 4-careno & 10,08 & Mirceno & 0,58 \\
\hline$\delta$-terpineno & 6,43 & $\beta$-pineno & 0,54 \\
\hline 1,8-cineol & 4,16 & Epi-biciclosesquifelandreno & 0,46 \\
\hline 0 -cineno & 3,46 & $\alpha$-gurjuneno & 0,40 \\
\hline$\alpha$-terpineol & 3,06 & Cariofileno & 0,39 \\
\hline$\alpha$-pineno & 1,94 & Ledol & 0,38 \\
\hline$\beta$-terpineno & 1,81 & $\alpha$-selineno & 0,22 \\
\hline J-cadineno & 1,56 & Espatulenol & 0,20 \\
\hline ledeno & 1,53 & Epiglobulol & 0,20 \\
\hline Aromadendreno & 1,31 & $\beta$-cadineno & 0,19 \\
\hline Globulol & 1,24 & Copaeno & 0,14 \\
\hline
\end{tabular}

${ }^{*}$ Teor do composto em relação ao total identificado.

O óleo essencial de melaleuca apresentou ação antifúngica sobre o crescimento in vitro de $S$. sclerotiorum e Fusarium spp., inibindo totalmente o desenvolvimento do micélio de ambos os fitopatógenos na concentração de $0,5 \%$ (Tabela 2).

Recente estudo comprovou a eficácia do óleo essencial de $M$. alternifolia em inibir o crescimento de alguns microrganismos patogênicos a humanos, incluindo Escherichia coli Escherich, Staphylococcus aureus Rosenbach, Pseudomonas aeruginosa Schroeter, Penicillium italicum Wehmer e Penicillium digitatum Sacc (ZHANG et al., 2018).

No que se refere a patógenos que causam danos em cultivos agrícolas, Barbosa et al. (2015) observaram que 50 L.L ${ }^{-1}$ do óleo essencial de melaleuca foi efetivo no controle de Colletotrichum musae B. \& M.A.C. Souza et al. (2015) reportaram redução de $99 \%$ do crescimento micelial de Cercospora beticola Sacc. com o uso de $1 \%$ de óleo essencial de melaleuca. Avaliando o efeito de controle in vitro do óleo de melaleuca sobre Botrytis cinérea Pers. e Rhizopus stolonifer (Ehrenb. Fr.) Vuill, patógenos de importância pós-colheita, Shao et al. (2013) observaram alta atividade contra a germinação de esporos e o crescimento micelial de ambos os microrganismos. Redução do crescimento micelial de Fusarium graminearum Schw., F. culmorum (Wm.G.Sm.) Sacc. e Pyrenophora graminea S. Ito \& Kurib. também foi verificado por Terzi et al. (2007), utilizando concentrações de óleo essencial de melaleuca a partir de 0,25 a $5 \%$. 
TABELA 2 - Diâmetro médio da colônia $(\mathrm{mm})$ de Sclerotinia sclerotiorum e dois isolados de Fusarium sp. em meio de cultura contendo diferentes concentrações do óleo essencial de Melaleuca alternifolia após 72 e 96 horas de incubação. Santa Maria - RS, 2019.

\begin{tabular}{cccc}
\hline & \multicolumn{2}{c}{ Diâmetro médio da colônia (mm) após 72 hs } \\
\cline { 3 - 4 } Tratamentos & S. sclerotiorum & \multicolumn{2}{c}{ Fusarium sp. } \\
\cline { 3 - 4 } & & T1R3 & T4R3 \\
\hline Controle & $58,84 \mathrm{~d}^{*}$ & $42,82 \mathrm{e}$ & $33,72 \mathrm{~d}$ \\
Controle álcool & $51,49 \mathrm{c}$ & $36,83 \mathrm{~d}$ & $33,35 \mathrm{~d}$ \\
$\mathbf{0 , 1} \%$ & $14,03 \mathrm{~b}$ & $23,84 \mathrm{c}$ & $25,09 \mathrm{c}$ \\
$\mathbf{0 , 2 5 \%}$ & $9 \mathrm{a}$ & $15,01 \mathrm{~b}$ & $14,16 \mathrm{~b}$ \\
$\mathbf{0 , 5 \%}$ & $9 \mathrm{a}$ & $9 \mathrm{a}$ & $9 \mathrm{a}$ \\
\hline $\mathbf{C V}(\%)^{\star *}$ & 6,36 & 6,42 & 3,71 \\
\hline
\end{tabular}

\begin{tabular}{cccc}
\hline & \multicolumn{3}{c}{ Diâmetro médio da colônia (mm) após 96 hs } \\
\cline { 3 - 4 } Tratamentos & \multirow{2}{*}{ S. sclerotiorum } & \multicolumn{2}{c}{ Fusarium sp. } \\
\cline { 2 - 4 } & & T1R3 & T4R3 \\
\hline Controle & $85 \mathrm{c}$ & $69,85 \mathrm{~d}$ & $47,84 \mathrm{~d}$ \\
\hline Controle álcool & $85 \mathrm{c}$ & $60,29 \mathrm{~d}$ & $46,66 \mathrm{~d}$ \\
\hline $\mathbf{0 , 1} \%$ & $42,64 \mathrm{~b}$ & $37,66 \mathrm{c}$ & $35,18 \mathrm{c}$ \\
\hline $\mathbf{0 , 2 5} \%$ & $9 \mathrm{a}$ & $27,31 \mathrm{~b}$ & $21,38 \mathrm{~b}$ \\
\hline $\mathbf{0 , 5} \%$ & $9 \mathrm{a}$ & $9 \mathrm{a}$ & $9 \mathrm{a}$ \\
\hline $\mathbf{C V}(\%)$ & 3,93 & 11,23 & 6,47 \\
\hline
\end{tabular}

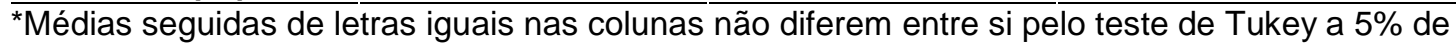
probabilidade de erro.

${ }^{* *}$ Coeficiente de variação.

Neste trabalho, foram observadas diferenças significativas das concentrações do óleo essencial de melaleuca avaliadas sobre o percentual de inibição de ambos os gêneros de fitopatógenos. Para $S$. sclerotiorum, as concentrações de 0,25 e $0,5 \%$ controlaram $100 \%$ o crescimento fúngico (Tabela 3 ), demonstrando potencial para uso agrícola.

Observou-se que a adição de álcool, necessária para promover a solubilização do óleo essencial no meio de cultura, também apresentou efeito de inibição de $S$. sclerotiorum e de um dos isolados de Fusarium sp. No entanto, o efeito inibitório do óleo de melaleuca foi significativamente superior para todos os isolados avaliados, mesmo na menor concentração $(0,1 \%)$ (Tabela 3$)$.

Evidenciou-se comportamento semelhante de ambos os isolados de Fusarium sp. em relação ao crescimento na presença das diferentes concentrações de óleo essencial de melaleuca, sendo que o percentual de inibição foi crescente com o aumento das doses avaliadas (Tabela 3). Os resultados deste estudo corroboram com informações descritas na literatura. Packer e Luz (2007) observaram atividade bacteriostática e fungistática do óleo de melaleuca frente aos microrganismos Staphylococcus aureus Rosenbach (ATCC 6538), Escherichia 
coli (ATCC 8739), Pseudomonas aeruginosa Schroeter (ATCC 9027) e Candida albicans Berkhout, destacando-se em relação aos óleos de copaíba, alecrim, andiroba e alho.

TABELA 3 - Percentual de inibição de crescimento micelial de Sclerotinia sclerotiorum e dois isolados de Fusarium sp. em meio de cultura contendo diferentes concentrações do óleo essencial de Melaleuca alternifolia após 96 horas de incubação. Santa Maria - RS, 2019.

\begin{tabular}{cccc}
\hline Tratamentos & S. sclerotiorum & \multicolumn{2}{c}{ Fusarium sp. } \\
\cline { 2 - 4 } & & T1R3 & T4R3 \\
\cline { 2 - 4 } Controle álcool & $0 \mathrm{c}^{*}$ & $10,96 \mathrm{~d}$ & $3,03 \mathrm{~d}$ \\
$\mathbf{0 , 1} \%$ & $55,73 \mathrm{~b}$ & $52,11 \mathrm{c}$ & $32,59 \mathrm{c}$ \\
$\mathbf{0 , 2 5} \%$ & $100 \mathrm{a}$ & $69,40 \mathrm{~b}$ & $68,12 \mathrm{~b}$ \\
$\mathbf{0 , 5 \%}$ & $100 \mathrm{a}$ & $100 \mathrm{a}$ & $100 \mathrm{a}$ \\
\hline $\mathbf{C V ~ ( \% )}$ & 3,64 & 11,73 & 5,98 \\
\hline
\end{tabular}

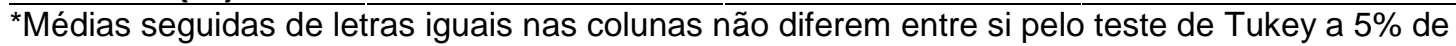
probabilidade de erro.

${ }^{\star *}$ Coeficiente de variação.

As distintas atividades biológicas associadas aos óleos essenciais dependem da composição, da concentração dos principais componentes e das possíveis interações sinérgicas com componentes menores (POWERS et al., 2018). Os óleos essenciais das plantas pertencentes à família Myrtaceae, a exemplo da melaleuca, goiabeira (Psidium guajava L.), goiaba-serrana (Acca sellowiana O. Berg.) e das diversas espécies do gênero Eucalyptus, apresentam uma classe de metabólitos secundários voláteis farmacologicamente e toxicologicamente eficazes, os quais são formados principalmente por terpenos e compostos aromáticos (NOURI-GANBALANI et al., 2016).

Em trabalho realizado por Powers et al. (2018), foram apresentados os componentes majoritários de 60 espécies bioativas, dentre elas M. alternifolia. Segundo os autores, o óleo essencial de melaleuca apresenta terpinen-4-ol $(47,5 \%)$, $\gamma$-terpinene $(20,2 \%)$ e $\alpha$-terpinene $(8,6 \%)$. Estes compostos denominados de terpenos e seus derivados possuem comprovado efeito antimicrobiano (LUTFI ; ROQUE, 2014; MARTINO et al., 2015), o que explica os resultados observados no presente trabalho, quanto ao controle dos fitopatógenos pela adição de óleo essencial de melaleuca.

A natureza lipossolúvel dos óleos essenciais possibilita a interação com estruturas celulares que possuem constituição lipídica, resultando no aumento da permeabilidade das membranas e consequente desequilíbrio eletrolítico e morte celular (CAVALCANTI et al., 2011). A danificação da membrana citoplasmática das lipoproteínas provoca vazamento citoplasmático, bem como esvaziamento e murcha das hifas (SANTOS et al., 2013; MAIA et al., 2015). Hammer et al. (2004) avaliaram a atividade antifúngica do óleo essencial de $M$. alternifolia sobre Candida albicans, Candida glabrata (Anderson) Meyer \& Yarrow e Saccharomyces cerevisiae Meyen ex E.C. Hansen. Os autores observaram alteração da permeabilidade e da fluidez da membrana entre as concentrações 0,25\% e 1,0\% 
do óleo de melaleuca, sugerindo ação antifúngica pelo comprometimento das funções e alteração das propriedades da membrana. Phongpaichit et al. (2004) analisaram a morfologia celular de culturas fúngicas através de microscopia eletrônica de varredura, e observaram ocorrência de colapso e desnaturação celular após exposição a extratos de produtos naturais. Considerando estas evidências, é provável que o mecanismo de ação dos óleos essenciais frente a microrganismos esteja relacionado com alteração da permeabilidade da membrana citoplasmática, cuja resultante é a morte celular.

Análises de cromatografia em óleo essencial de melaleuca indicam terpenoides oxigenados como os principais componentes, dentre eles o terpinen4-ol é o mais efetivo, estando presente entre 30 a $40 \%$ da composição (CARSON et al., 2006). O Terpinen-4-ol é o componente que detêm a principal atividade antimicrobiana do óleo de melaleuca, pois induz perda da membrana, interferindo na integridade e fisiologia bacteriana (OLIVEIRA et al., 2011).

Para otimizar a atividade antimicrobiana, a norma internacional ISO 4730 requer dois componentes característicos do óleo comercial de melaleuca e o quimiótipo de terpinen-4-ol deve ter um teor mínimo de terpinen-4-ol de 30\% e um teor máximo de 1,8-cineol de 15\%. Yu et al. (2015) confirmaram que terpinen-4-ol e 1,8-cineol, constituintes majoritários do óleo essencial de melaleuca, atuam principalmente nas membranas celulares e organelas de Botrytis cinerea (De Bary) Whetzel, respectivamente, e quando combinados são semelhantes ao óleo essencial de melaleuca na atividade antifúngica. Esses resultados vão ao encontro dos resultados obtidos neste trabalho, auxiliando na compreensão do modo de atuação do óleo de melaleuca no controle de fitopatógenos e confirmando o potencial deste componente natural para a composição de bioprodutos com aplicação na agricultura.

\section{CONCLUSÃO}

O óleo essencial de Melaleuca alternifolia apresenta ação antifúngica sobre Sclerotinia sclerotiorum e Fusarium sp.

A concentração de $0,25 \%$ do óleo de melaleuca proporcionou $100 \%$ de controle de S. sclerotiorum e aproximadamente $70 \%$ de controle dos isolados do gênero Fusarium em condições in vitro.

O crescimento de $S$. sclerotiorum e Fusarium sp. foi inibido na concentração de $0,5 \%$ do óleo essencial de melaleuca, o que demonstra o potencial da espécie para a formulação de biofungicidas destinados à agricultura.

\section{REFERÊNCIAS}

BARBOSA, M. S.; VIEIRA, G. H. C.; TEIXEIRA, A. V. Biological activity in vitro propolis and essentials oils on the Colletotrichum musae isolated in Musa spp. Brazilian Journal of Medicinal Plants, v. 17, p. 254-261, 2015. Disponível em: $<$ http://www.scielo.br/pdf/rbpm/v17n2/1516-0572-rbpm-17-2-0254.pdf>. $\quad$ DOI: 10.1590/1983-084X/13_063

BIANCHINI, A.; MARINGONI, A. C.; CARNEIRO, S. M. T. P. G. Doenças do feijoeiro. In: KIMATI, H.; AMORIM, L.; REZENDE, J. A. M.; BERGAMIN FILHO, A.; 
CAMARGO, L. E. A. Manual de fitopatologia: doenças das plantas cultivadas. 4. ed. São Paulo: Agronômica Ceres, 2005. v. 2, cap. 37, p. 333-349.

BOUDH, S.; SINGH, J. S. Pesticide contamination: environmental problems and remediation strategies. In: BHARAGAVA, R.M.; CHOWDHARY, P. (Eds.). Emerging and Eco-Friendly Approaches for Waste Management. Singapore: Springer, 245-269, 2019.

BURIGO, A. Impacto dos Agrotóxicos na alimentação, saúde e meio ambiente. Cartilha "Agrotóxicos: impactos e alternativas". Escola Politécnica de Saúde Joaquim Venâncio (EPSJV/Fiocruz). 2016, 30 p. Disponível em: <http://www.mobilizadores.org.br/wp-content/uploads/2016/08/CartilhaAgrotoxicos-final.pdf>.

CARSON, C. F.; HAMMER, K. A.; RILEY, T. V. Melaleuca alternifolia (tea tree) oil: a review of antimicrobial and other medicinal properties. Clinical Microbiology Reviews, v. 19, n. 1, p. 50-62, 2006. Disponível em: <https://www.ncbi.nlm.nih.gov/pubmed/16418522>.DOI:10.1128/CMR.19.1.5062.2006

CAVAlCANTI, Y. W.; PÉREZ, A. L. A. L.; XAVIER, G. D. R.; ALMEIDA, L. F. D. Efeito inibitório de óleos essenciais sobre microrganismos do canal radicular. Revista de Odontologia da UNESP, v. 40, n. 5, p. 208-214, 2011. Disponível em: $<$ https://www.revodontolunesp.com.br/article/588018ef7f8c9d0a098b4ec9/pdf/rou40-5-208.pdf>.

FELIPE, L. O.; BICAS, J. L. Terpenos, aromas e a química dos compostos naturais. Química Nova na Escola, v. 39, n. 2, p. 120-130, 2017. Disponível em: <http://qnesc.sbq.org.br/online/qnesc39_2/04-QS-09-16.pdf>. DOI:10.21577/01048899.20160068

FERREIRA, D. F. Sisvar: a computer statistical analysis system. Ciência e Agrotecnologia, v. 35, n. 6, p. 1039-1042, 2011. Disponível em: <http://www.scielo.br/pdf/cagro/v35n6/a01v35n6.pdf>. DOI:10.1590/S141370542011000600001.

FIALHO, R. O.; PAPA, M. F. S.; PEREIRA, D. A. S.; Efeito fungitóxico de óleos essenciais sobre Phakopsora euvitis, agente causal da ferrugem da videira. Arquivos do Instituto Botânico, v.82, n.1, p.1-7, 2015. Disponível em: <https://www.scielo.br/pdf/aib/v82/1808-1657-aib-00070202013.pdf> DOI:10.1590/1808-1657000702013

HAMMER, K. A.; CARSON, C. F., RILEY, T. V. Antifungal effects of Melaleuca alternifolia (tea tree) oil and its components on Candida albicans, Candida glabrata and Saccharomyces cerevisiae. Journal of Antimicrobial Chemotherapy, v. 53, n. $6, \quad$ p. 1081-1085, 2004 Disponível em: 
<https://pdfs.semanticscholar.org/23df/7ef24e6955d89e91d790099adb34cfecfcab. pdf?_ga=2.10737331.643918500.1570106352-634975506.1570106352>. $\quad$ DOl: $10.1093 / \mathrm{jac} / \mathrm{dkh} 243$

JAISWAL, S.; SINGH, D. K.; SHUKLA, P. Gene editing and systems biology tools for pesticide bioremediation: A review. Frontiers in Microbiology, v. 10, Article 87, p. 1-13, 2019. Disponível em: <https://www.ncbi.nlm.nih.gov/pmc/articles/PMC6396717/pdf/fmicb-10-00087.pdf>. DOI:10.3389/fmicb.2019.00087

LEITE, R. M. V. B. C. Ocorrência de doenças causadas por Sclerotinia sclerotiorum em girassol e soja. Londrina: Embrapa Soja, Comunicado técnico 76, 2005. 3p.

LOPES, C. V. A.; ALBUQUERQUE, G. S. C. Agrotóxicos e seus impactos na saúde humana e ambiental: uma revisão sistemática. Saúde e Debate, v. 42, n. 117, p. 518-534, 2018.2 Disponível em: <http://www.scielo.br/pdf/sdeb/v42n117/0103-1104-sdeb-42-117-0518.pdf>. DOI: 10.1590/0103-1104201811714

LUTFI, M.; ROQUE, N. F. Histórias de Eugênias. Química Nova na Escola, v. 36, n. $4, \quad$ p. 252-260, 2014.2 Disponível em: <http://qnesc.sbq.org.br/online/qnesc36_4/03-QS-188-12.pdf>.DOI:10.5935/01048899.20140030

MARTINO, L.; NAZZARO, F.; MANCINI, E.; DE FEO, V. Essencial Oils from Mediterranean Aromatic Plants. The Mediterranean Diet. Academic Press. Chap. 58, p. 649-661, 2015. Disponível em: <https://doi.org/10.1016/B978-0-12-4078499.00058-0>. DOI: 10.1016/B978-0-12-407849-9.00058-0.

MAIA, F. T.; DONATO DE, A.; FRAGA, E. M. Review: Antigungal activity of essential oils of plants. Revista Brasileira de Produtos Agroindustriais, v. 17, p. 105-116, 2015.2 Disponível em: <http://www.deag.ufcg.edu.br/rbpa/rev171/Art17111.pdf>.

MARTINS, J. A. S.; SAGATA, E.; SANTOS, V. A.; JULIATTI, F. C. Avaliação do efeito do óleo de Melaleuca alternifolia sobre o crescimento micelial in vitro de fungos fitopatogênicos. Bioscience Journal, v. 27, p. 49-51, 2011. Disponível em: < http://www.seer.ufu.br/index.php/biosciencejournal/article/view/7379/6840>.

MICHEREFF, S. J.; ANDRADE, D. E. G. T.; PERUCH, L. A. M.; MENEZES, M. Importância dos patógenos e das doenças radiculares em solos tropicais. In: MICHEREFF, S. J.; ANDRADE, D. E. G. T.; MENEZES, M. (Eds.). Ecologia e manejo de patógenos radiculares em solos tropicais. Recife: UFRPE, Imprensa Universitária, p. 1-18.2005. 
MIGLIORINI, P.; MILANESI, P. M.; MEZZOMO, R.; MACIEL, C. G.; MUNIZ, M. F. B. Fusarium solani and F. oxysporum: Etiological agents of damping off in crambe. Revista Brasileira de Ciências Agrárias, v. 13, n. 1, p. 1-7, 2018. Disponível em: $<$ http://agraria.pro.br/ojs2.4.6/index.php?journal=agraria\&page=article\&op=view\&p ath\%5B\%5D=agraria_v13i1a5510\&path\%5B\%5D=5035>.

DOI:10.5039/agraria.v13i1a5510

MOORMAN, T. B. Pesticide degradation by soil microorganisms: Environmental, ecological and management effects. In: HATFIELD, J.L. (Ed.). Soil Biology: effects on soil quality. 1. Ed. eBook, Boca Raton: CRC Press, 2018. p. 127-172. Disponível em: <https://doi.org/10.1201/9781351076692>. DOI: $10.1201 / 9781351076692$

NICOLODI-CAMERA, J.; KOEFENDER, J.; FERREIRA-FERNANDES, A. M.; SODER, E. M. W. Atividade antifungica de extratos aquosos de plantas medicinais no crescimento micelial de Fusarium graminearum Schwabe. Multitemas, v. 23, n. 54, p. 141-152, 2018. Disponível em: <http://www.multitemas.ucdb.br/article/view/1723>.

DOI:10.20435/multi .v23i54.1723

NOURI-GANBALANI, G.; EBADOLLAHI, A.; NOURI, A. Chemical composition of the essential oil of Eucalyptus procera Dehnh. and its insecticidal effects against two stored product insects. Journal of Essential Oil-Bearing Plants JEOP, v. 19, n. $5, \quad$ p. 1234-1242, 2016. Disponível em: <https://www.tandfonline.com/doi/abs/10.1080/0972060X.2016.1178606>. DOI:10.1080/0972060X.2016.1178606

OLIVEIRA, A. C. M.; FONTANA, A.; NEGRINI, T. C.; NOGUEIRA, M. N. M.; BEDRAN, T. B. L.; ANDRADE, C. R.; SPOLIDORIO, L. C.; SPOLIDORIO, D. M. P. Emprego do óleo de Melaleuca alternifolia Cheel (Myrtaceae) na odontologia: perspectivas quanto à utilização como antimicrobiano alternativo às doenças infecciosas de origem bucal. Revista Brasileira de Plantas Medicinais, v. 13, n. 4 , p., 2011. Disponível em: <http://dx.doi.org/10.1590/S151605722011000400015>. DOI: 10.1590/S1516-05722011000400015

PACKER, J. F.; LUZ, M. M. S. Método para avaliação e pesquisa da atividade antimicrobiana de produtos de origem natural. Revista Brasileira de Farmacognosia, v. 17, n. 1, p. 102-107, 2007. Disponível em: <http://www.scielo.br/pdf/rbfar/v17n1/a19v17n1.pdf>. DOI:10.1590/S0102695X2007000100019

PETERS, M. Essential oils - Historical significance, chemical composition and medicinal uses and benefits. Nova Science Publishers, New York, 2016, $215 \mathrm{p}$. 
POWERS, C. N.; OSIER, J. L.; McFEETERS, R. L.; BRAZELL, C. B.; OLSEN, E. L.; MORIARITY, D. M.; SATYAL, P; SETZER, W. N. Antifungal and cytotoxic activities of sixty commercially-available essential oils. Molecules, v. 23, n. 7, p. 1549, 2018. Disponível em: <https://ncbi.nlm.nih.gov/pubmed/29954086>. DOI:10.3390/molecules23071549

PHONGPAICHIT, S.; PUJENLOB, N.; RUKACHAISIRIKUL, V.; ONGSAKUL, M. Antifungal activity from leaf extracts of Cassia alata L., Cassia fistula L. and Cassia tora L. Songklanakarin Journal of Science and Technology, v. 26, p. 741-748, 2004.

RIBEIRO, J. G.; SERRA, I. M. R. S.; ARAUJO, M. U. P. Uso de produtos naturais no controle de antracnose causado por Colletotrichum gloeosporioides em mamão. Summa Phytopathologica, v. 42, n. 2, p. 160-164, 2016. Disponível em: <http://www.scielo.br/scielo.php?pid=S0100-

54052016000200160\&script=sci_abstract\&tIng=pt>. DOI:10.1590/0100-5405/2023

SHAO, X.; WANG, H.; XU, F.; CHENG, S. Effects and possible mechanisms of tea tree oil vapor treatment on the main diseases in postharvest strawberry fruit. Postharvest Biology and Technology, v. 77, p. 94-101, 2013. Disponível em: <https://www.sciencedirect.com/science/article/abs/pii/S0925521412002645>.

DOI:10.1016/j.postharvbio.2012.11.010

SANTOS, G. R.; BRUM, R. B. C. S.; CASTRO, H. G.; GONÇALVES, C. G.; FIDELIS, R. R. Efeito de óleos essenciais de plantas medicinais sobre a helmintosporiose do capim Tanzânia. Revista Ciência Agronômica, v. 44, n. 3, p.587-593, 2013. Disponível em: <http://dx.doi.org/10.1590/S180666902013000300022>. DOI: 10.1590/S1806-66902013000300022

SOUZA, A. D.; ROGGERIO, T. U; FURLAN, M. R.; AOYAMA, E. M. Óleo de melaleuca (Melaleuca alternifolia Maiden \& Betche, Cheel) no controle de cercosporiose em beterraba. Revista Brasileira de Plantas Medicinais, v. 17, $\mathrm{n}$. 4, supl. III, p.1078-1082, $2015 . \quad$ Disponível em: <http://www.scielo.br/scielo.php?script=sci_arttext\&pid=S1516-

05722015000701078>. DOI:10.1590/1983-084X/14_042

SouzA, A. A.; GeRvasio, R. C. R. G.; LIMA, M. N. R.; NETO, I. S. L. Empoderamento de agricultores no uso de caldas alternativas para controle de pragas em hortaliças em horta comunitária de base agroecológica. Revista de Extensão da UNIVASF, v. 6, n. 1, p. 80-88, 2018. Disponível em: <http://www.periodicos2.univasf.edu.br/index.php/extramuros/article/view/1284/2>.

TAYLOR, A.; COVENTRY, E.; HANDY, C.; WEST, J. S.; YOUNG, C. S.; CLARKSON, J. P. Inoculum potential of Sclerotinia sclerotiorum sclerotia depends on isolate and host plant. Plant Pathology, v. 67, n. 6, p. 1286-1295, 2018. Disponível em: 
<https://bsppjournals.onlinelibrary.wiley.com/doi/abs/10.1111/ppa.12843>.

DOI:10.1111/ppa.12843

TERZI, V.; MORCIA, C.; FACCIOLI, P.; VALE, G.; TACCONI, G.; MALNATI, M. In vitro antifungal activity of the tea tree (Melaleuca alternifolia) essential oil and its major components against plant pathogens. Letters in Applied Microbiology, v. 44, n. 6, p. 613-618, 2007. Disponível em: <https://www.ncbi.nlm.nih.gov/pubmed/17576222>. DOl:10.1111/j.1472765X.2007.02128.x

YU, D. J.; WANG, X.; SHAO, F.; XU; WANG, H. Antifungal modes of action of tea tree oil and its two characteristic components against Botrytis cinerea. Journal of Applied Microbiology, v. 119, p. 1253-1262, 2015. Disponível em: <https://onlinelibrary.wiley.com/doi/full/10.1111/jam.12939>.

DOI:10.1111/jam.12939

ZHANG, X.; GUO, Y.; GUO, L.; JIANG, H.; JI, Q. In vitro evaluation of antioxidant and antimicrobial activities of Melaleuca alternifolia essential oil. BioMed Research International, $8 p ., \quad 2018 . \quad$ Disponível em: <https://www.hindawi.com/journals/bmri/2018/2396109>. DOI: doi.org/10.1155/2018/2396109 